\title{
Editorial: Welcome to the Special Issue on the Psychology of Religion in China
}

\author{
Lewis R. Rambo
}

Published online: 30 August 2012

(C) Springer Science+Business Media, LLC 2012

Welcome to this special issue of Pastoral Psychology on the Psychology of Religion in China. As the twenty-first century unfolds, the People's Republic of China plays one of the central roles on the contemporary world stage. With more than 1.3 billion people, China has the largest population in the world, and its economy has sustained one of the most robust growth rates in the last 30 years.

Understanding this vast and complex society and culture is thus crucial and urgent. This special issue brings together psychologists from China and the United States for a sustained exploration of the psychology of religion. We believe that the theories and methods of psychology of religion provide illuminating and creative insights into the human predicament.

By expanding the horizons of psychology of religion through vigorous and critical engagement with colleagues from two profoundly different cultures and histories, we enrich our own understanding of the nature of psychology and of the nature of religion.

This special issue is particularly significant for me personally and professionally. Since my marriage to my wonderful wife (a native of Shanghai) in 2001, I have found a second home in China; we now live half the time in China and the other half in California. And professionally, this special issue is important because it embodies one of my goals for making Pastoral Psychology an international forum for psychology and religion. Over the last decade, we have sought to bring together the voices of people from around the world as we seek to provide resources for serving the needs of those facing the many joys and challenges of life.

This special issue was created through the hard work and energy of many people. First and foremost, I want to thank Al Dueck and Buxin Han for being guest editors. Through their efforts, they invited, nurtured, and encouraged all the authors whose papers appear in this issue. Editorial Board members James Emerson and Donald Capps have given sustained support and guidance. Editorial associates Nathan Carlin and Kathy McKay have been extraordinarily helpful through their enthusiasm for this special issue and their excellent editing skills.

I hope you enjoy and learn from this marvelous panorama of papers about a wide range of fascinating and important topics on the psychology of religion in China.

L. R. Rambo ( $\bowtie)$

Yonsei University, Seoul, Korea

e-mail: lewisrayrambo@yahoo.com 